\title{
Application of Emulsion Liquid Membrane Using Green Surfactant for Removing Phenol from Aqueous Solution: Extraction, Stability and Breakage Studies
}

\author{
Ahmed A. Mohammed ${ }^{1}$, Rasha Waleed Al-Khateeb ${ }^{1,2^{*}}$ \\ 1 Environmental Engineering Department, College of Engineering University of Baghdad, Baghdad, Iraq \\ 2 Physics Science Department, College of Science, University of Baghdad, Baghdad, Iraq \\ * Corresponding author's e-mail: rasha.w@sc.uobaghdad.edu.iq
}

\begin{abstract}
Emulsion Liquid Membrane (ELM) has garnered much attention, for its simple operation and high selectivity for the target solute. For an ELM process to be successful, emulsion stability and formulation of liquid membrane are the two main criteria. This study investigated an ELM formulation to identify a suitable green surfactant over the ordinary ones to reduce the utilization of chemicals. The stability of water-in-oil-in-water (w/o/w) was assessed in the following ways, by altering the concentrations of the egg yolk and $\mathrm{NaOH}$, homogenizer speed, and emulsification time. To ascertain the favorable conditions for phenol extraction, several experiments were performed, adopting the batch process, which included many parameters, like the influence exerted by the $\mathrm{pH}$ of the external feed, concentration of surfactant, concentration of the internal phase, time of emulsification, homogenization speed and mixing time. Lower breakage and greater extraction efficiency $(0.83 \%$ and $82.06 \%$, respectively) were attained at $3.5 \mathrm{pH}$ of the external feed, $4 \%(\mathrm{v} / \mathrm{v})$ of the surfactant, $0.1 \mathrm{M}$ of NaOH, $7 \mathrm{~min}$ of emulsification time, $5800 \mathrm{rpm}$ of homogenizer speed and 3 minutes of mixing time. From the results of this study, egg yolk emerged as a good green surfactant. Thus, the ELM process holds promise as an effective technology for stripping phenol from aqueous solutions.
\end{abstract}

Keywords: ELM, phenol, green surfactant, stability, extraction.

\section{INTRODUCTION}

Phenol is a corrosive and nerve poison, releases fumes that irritate the eyes, nose and skin. Hence, employees especially need to be protected, and exposure to phenol must be controlled. According to the National Institution for Occupation Safety and Health (NIOSH) no one should experience phenol exposure at concentrations that exceed $20 \mathrm{mg} / \mathrm{m}^{3}$, on a time-weighted average 10-hour work day or a 40-hour work schedule per week. Not only to humans, phenol is also very toxic to fish particularly, although it affects all animals. Fish especially get contaminated when exposed to phenol in the marine environment, even at concentrations of $0.1-1.0 \mathrm{ppm}$. The maximum permissible phenol concentrations in the effluents of drinking and industrial waste water should be less than 0.1 and $1 \mathrm{mg} / \mathrm{L}$, respectively (Verschueren 1977, Mahvi et al. 2007). Substantial quantities of phenol are released in the waste streams of several industries including the petrochemical plants, petroleum refineries, pesticide manufacturing units, as well as petroleum and activities in the oilfields (Xin Zhao 2006, Moussavi et al. 2009). Thus, the phenol discharged into the water resources, on a global level, has precipitated in many countries, serious water pollution issues and been even life-threating, particularly when the populace is solely dependent on these resources for drinking water. High phenol concentrations induce the water to change in odor, color, and taste (Bazrafshan et al. 2019).

The methods most frequently employed in phenol removal from aqueous solutions include the following: adsorption (Roostaei and Tezel 
2004, Dehmani et al. 2020), advanced oxidation (Jiang and Mao 2012), biological treatment (Arutchelvan et al. 2006, Shibata et al. 2006, Jiang et al. 2010), electrocoagulation (Ahmed 2008, Abdelwahab et al. 2009, Hernández-Francisco et al. 2017), flotation (Wilberg et al. 2000) and emulsion liquid membrane, etc. Low efficiency in terms of performance with small concentrations of inorganic and organic contaminants, high operational expenditure incurred, accumulation of secondary sludge, extended treatment and operational times, are some of the factors which pose restrictions on the success of the methods cited above (Mohammed and Selman 2018). In light of the state-of-the-art research works, to date the simplest method of chemical contaminant removal from wastewater is through the use of the emulsion liquid membrane (ELM) technique. On comparison with the ELM, the usage of classical semi-permeable and permeable membranes in reverse osmosis, ultrafiltration and microfiltration displayed limitations induced by sensitivity and difficult operating conditions, besides high maintenance and operating expenditures, heightened power consumption and huge quantities of sludge (Hussein et al. 2019).

Numerous studies in the literature advocate the ELM technique which has now earned massive popularity (Gürel et al. 2005, Raji et al. 2017, Kusumastuti et al. 2018, Seifollahi et al. 2019) for its unique features over other conventional methods used in the recovery and removal of inorganic and organic pollutants from wastewater. These characteristics include simplicity and easy operation process, high degree of efficiency in removal and recovery, simultaneous stripping and extraction, high flux, low operating expenditure and low capital cost (Kohli et al. 2019, Mohammed et al. 2020). Overall, the ELM is a three-phase dispersion system, which includes an immiscible organic phase (membrane) and a miscible liquid aqueous phase (internal and external). The emulsion is created by homogenization of the internal aqueous phase and organic oil phase via high-speed emulsification, in the presence of a stabilizing agent to help maintain the emulsion stability. This is done by preventing the internal phase droplets from coalescing to produce the water-in-oil (w/o) emulsion. This is then dispersed in an external feed phase to form the water-in-oil-in-water (w/o/w) emulsion (Jiao et al. 2013, Mohammed et al. 2020). Normally, the dispersed internal phase droplet size distribution is 1-100 $\mu \mathrm{m}$ (Devulapalli and Jones 1999).
The concept of contaminant separation utilizing emulsion liquid membrane involves the dispersal of the emulsion into the aqueous feed phase and the transportation of the constituents across the organic oil phase to arrive at the internal stripping phase as droplets. The principal hurdle in the ELM process is emulsion stability, meaning the breakdown of the emulsion to release the internal phase of the outside emulsion droplet. Therefore, it is necessary to reach the target stability level to overcome the application problems in the ELM system on an industrial scale through the use of the appropriate surfactant (Ahmad et al. 2012). In the literature, the use of many surfactant types has been cited, among which span 80 , is extensively employed to produce a milky-white emulsion.

To the best of our knowledge, the earlier studies had never assessed the stability and efficiency of the ELM using egg yolk as a green surfactant. The focus of our investigation was to estimate the efficacy of the egg yolk as a surface-active agent in terms of the extraction efficiency and ELM stability. The study intended to report the influence exerted by the variables involved in the emulsion preparation and different process parameters, namely surfactant concentration, homogenizer speed, mixing speed, emulsification time, and extraction time. The goal was to show also the ways in which the concentration of the internal phase and the $\mathrm{pH}$ of the feed solution affected the emulsion stability and phenol extraction efficiency.

\section{MATERIALS AND EXPERIMENTAL METHODS}

\section{Materials}

The membrane phase is composed of surfactant and diluent. The egg yolk acts as the surfactant (structure shown in Figure 1a) and xylene was the diluent (98\% purity); the physical properties are listed in Table 1. The sodium hydroxide $(\mathrm{NaOH})$ (Thomas Baker-India), was used as the internal phase. The feed solution used at different values of $\mathrm{pH}$ contained $100 \mathrm{mg} / \mathrm{L}$ phenol. The phenol solution was prepared by dissolving a specific quantity in distilled water (structure shown in Figure 1b). 
Table 1. Physical properties of egg yolk

\begin{tabular}{|c|c|}
\hline Physical properties of egg yolk & Value at $20^{\circ} \mathrm{C}$ \\
\hline $\mathrm{pH}$ & 6.13 \\
\hline Density & $1027 \mathrm{~kg} / \mathrm{m}^{3}$ \\
\hline Viscosity & $1.499 \mathrm{k}(\mathrm{Pa} \mathrm{s})^{\mathrm{n}}$ \\
\hline
\end{tabular}

\section{Membrane preparation}

The emulsion was prepared in a $100 \mathrm{~mL}$ glass beaker, utilizing an SR30 homogenizer, at the appropriate speed and mixing time. The entire preparation process was performed at room temperature. The emulsion liquid membrane was prepared by dissolving egg yolk (green surfactant) in xylene (diluent). The $\mathrm{NaOH}$ solution, regarded as a supplementary, was added slowly to the membrane phase, as the mixture was being homogenized (as shown in Figure 2).

\section{Extraction procedure by emulsion liquid membrane}

First, crystal phenol was dissolved with a suitable quantity of distilled water to prepare $250 \mathrm{~mL}$ of $100 \mathrm{mg} / \mathrm{L}$ of phenol solution in a $400 \mathrm{~mL}$ beaker. This phenol solution was prepared prior to the preparation of the $\mathrm{W} / \mathrm{O}$ emulsion. Then the $\mathrm{W} / \mathrm{O}$ emulsion was poured into the external phase (phenol solution). At specific time intervals, the samples were drawn while the mixture was being continually stirred. All the samples were filtered through a

Table 2. Operating variable in EML system

\begin{tabular}{|l|c|}
\hline \multicolumn{1}{|c|}{ Variable } & Range \\
\hline EY concentration $\%(\mathrm{v} / \mathrm{v})$ & $3 ; 4 ; 5$ \\
\hline Emulsification time $(\mathrm{min})$ & $4 ; 7 ; 10$ \\
\hline Homogenizer speed $(\mathrm{rpm})$ & $3000 ; 5800 ; 12700$ \\
\hline Stirrer speed $(\mathrm{rpm})$ & $150 ; 250 ; 350$ \\
\hline $\mathrm{NaOH}$ concentration $(\mathrm{M})$ & $0.05 ; 0.1 ; 0.2$ \\
\hline
\end{tabular}

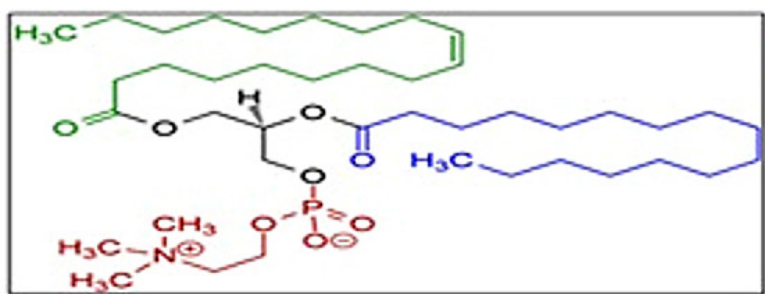

(a)
$0.25 \mu \mathrm{m}$-bore filter syringe. A summary of the conditions of the operation is given in Table 2 .

\section{Analysis and calculations}

The phenol concentration in the external phase, is calculated using the UV spectrophotometer (thermospectronic, USA). The phenol concentration was calculated using the calibration curve and standard method. The extraction efficiency is calculated according to Eq. (1) below:

$$
E \%=\frac{\left(c_{\text {in }}-c_{t}\right)}{c_{\text {in }}} \cdot 100 \%
$$

where: $c_{\text {in }}$ refers to the initial concentration of phenol in the feed phase, and $c_{t}$ indicates the concentration of phenol at time $t$, through the extraction stage.

The emulsion breakage is found using, Eq. (2) below:

$$
B \%=\frac{v_{i}}{v_{\text {int }}} \cdot 100 \%
$$

where: $v_{i}$ indicates the volume of the internal phase, which leaks into the feed phase and $v_{\text {int }}$ represents the initial volume of the internal phase.

The mass balance from the feed phase measured prior to and post the contact, were used to determine through Eq. (3) (Sabry et al. 2007, Chiha et al. 2010).

$$
v_{i}=\frac{v_{E_{0}}\left(10^{-p H_{0}}-10^{-p H}\right)}{\left(10^{-p H}-c_{O H}^{i n t}\right)}
$$

where: $v_{E_{0}}$ is the initial volume of the feed phase, $C_{O H}^{i n t}$ indicates the initial $\mathrm{OH}$ concentration in the internal phase, the $\mathrm{pH}_{0}$ signifies the initial concentration of the $\mathrm{pH}$ in the feed phase and $p H$ refers to the $\mathrm{pH}$ of the feed phase after a time interval.

\section{PHENOL STRUCTURE}
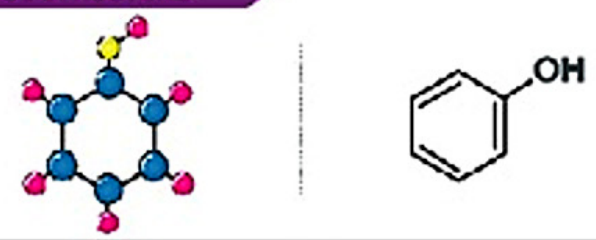

Figure 1. (a) Egg yolk structure Phosphatidyl choline, phospholipid in lecithin. Red represents phosphate group and choline; Black represents glycerol; Green represents unsaturated fatty acid; Blue represents saturated fatty acid. (b) Phenol structure 


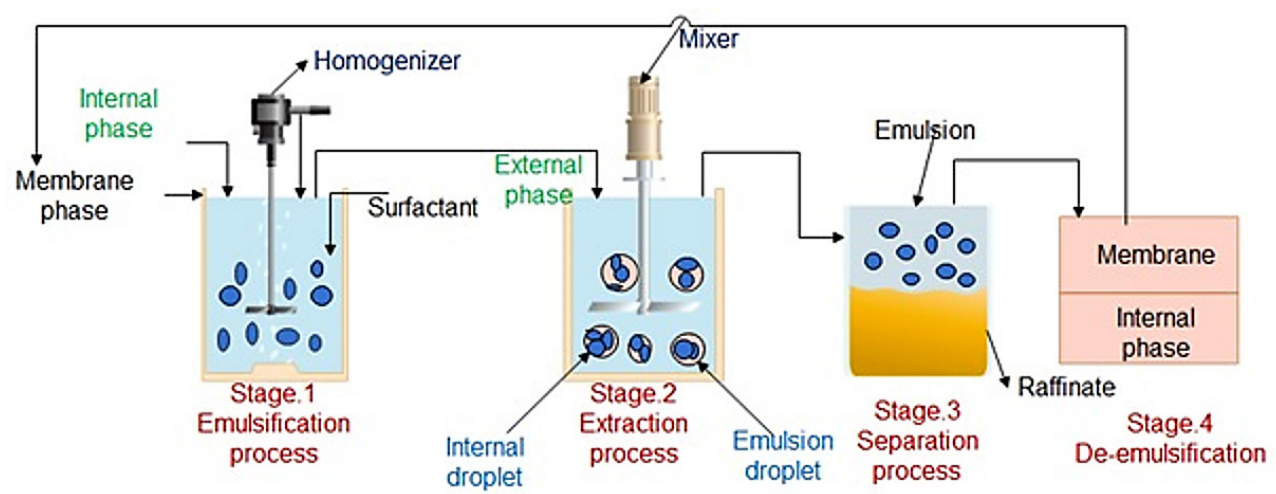

Figure 2. Schematic diagram of ELM process

\section{RESULTS AND DISCUSSIONS}

\section{Effect of $\mathrm{pH}$ in feed solution and contact time}

In this study, the investigations were done through various $\mathrm{pH}$ settings in the 3.5-9.5 range limit, to ascertain the influence exerted by the $\mathrm{pH}$ in the external phase on phenol extraction. Figure 3 shows the effect of the $\mathrm{pH}$, revealing the highest extraction efficiency at $\mathrm{pH}=3.5$. The emulsion used was formulated using equal volumes of $\mathrm{xy}-$ lene and stripping phase. the surfactant concentration was $4 \%(\mathrm{~V} / \mathrm{V})$, with homogenizer speed of $5800 \mathrm{rpm}, 7 \mathrm{~min}$ of emulsification time, and an initial phenol concentration of $100 \mathrm{ppm}$, keeping the treat ratio of the emulsion to feed solution at 1:5. Above this value $(\mathrm{pH}=6.5)$, the efficiency of extraction began to decrease slightly, reaching its minimum value at $(\mathrm{pH}=9.5)$, this behavior is because during the extraction process, The release of the internal phase via the ELM breaking raises the $\mathrm{pH}$ of the feed phase. As a result, decreasing the $\mathrm{pH}$ during the later stages of extraction successfully inhibited the increase in the external phase concentration (Park 2006). As a result, $\mathrm{pH}$ 3.5 was chosen for feed solution in this work.

Extraction contact time is defined as the time period when the liquid emulsion and the feed phase stay in contact while the system is continually stirred. The extraction contact time is regarded as a significant limitation in the ELM process.

In this study, an investigation of contact time effect was done, via optimum experimental conditions and the results obtained are plotted in Figure 3. Here, within the first 90 seconds, $70 \%$ of the phenol extraction efficiency was observed. With increasing extraction time to 120 seconds, the extraction efficiency was noted to increase slightly and achieve the optimal value (75\%). However, at a longer extraction time of $150 \mathrm{sec}-$ onds, as light drop was evident in the phenol extraction and stripping efficiency. This was largely caused by the long period of contact, and the subsequent increase in the transport of water from the internal droplets into the feed solution, which in turn resulted in the membrane swelling phase and thus raised the level of emulsion breakage.

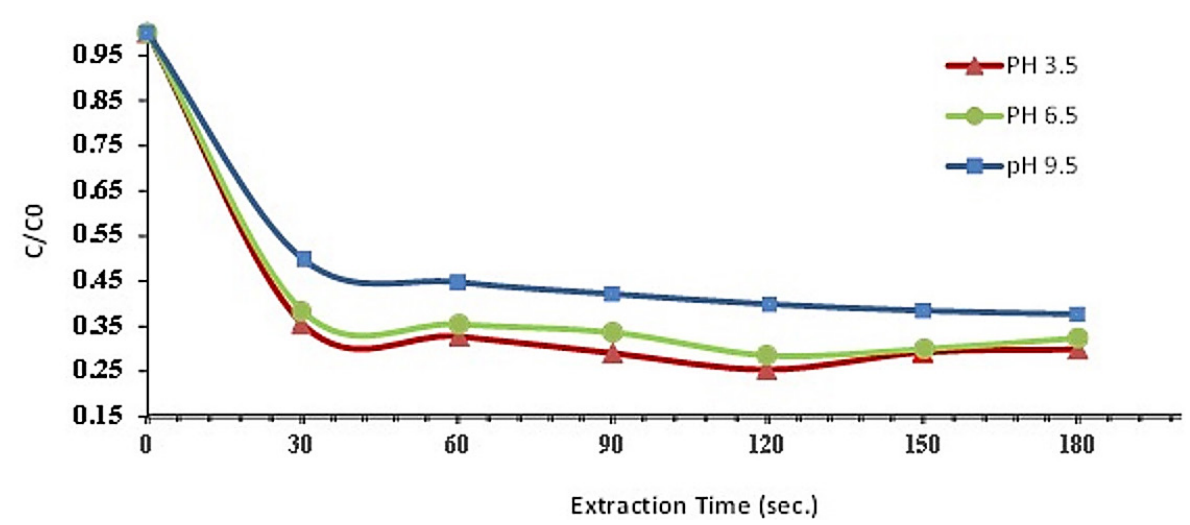

Figure 3. $\mathrm{pH}$ effect on phenol extraction ( $4 \% \mathrm{v} / \mathrm{v}$ EY; O/I ratio: 1:1; $0.1 \mathrm{M} \mathrm{NaOH}$; homogenizer speed: $5800 \mathrm{rpm}$; ET: $7 \mathrm{~min}$; mixing speed $250 \mathrm{rpm})$. 


\section{Effect of egg yolk concentration}

In the course of the experiment, it became clear that surfactant concentration ranks among the most influential parameters that affect the ELM efficiency, in terms of extraction and stability. The surfactant is best described as a polar organic compound having a hydrophilic head and hydrophobic tail. It is impossible to disperse the internal aqueous phase into the oil phase, in the absence of the surfactant, thus preventing the formation of the emulsion. The egg yolk used in the present study, as a green surfactant was to reduce the usage of chemicals in the emulsion liquid membrane procedure.

The amino acids present in the egg yolk proteins facilitate the egg yolk to act as an emulsifier, as certain amino acids repel water and others operate in the opposite manner. When the egg proteins mix with the oil and water, one part of the protein will adhere to the water, while another will stick to the oil. These investigations thus studied the effect of the surfactant concentration on the emulsion stability and phenol extraction efficiency, at the egg yolk/solvent volume percentages of 2, 3, 4 and 5\% (as shown in Figure 4). By raising the egg yolk concentration from 3 to $4 \%$ the stability of emulsion was observed to improve. However, the results of the extraction efficiency are not shown in Figure 4, when the egg yolk concentration was below $2 \%(\mathrm{v} / \mathrm{v})$ because instantaneous emulsion breakage was clearly observed even without any calculations. The $3 \%(\mathrm{v} / \mathrm{v})$ egg yolk concentration was found insufficient to surround the aqueous internal phase, causing membrane instability and breakup $(1.56 \%)$, with extraction efficiency of $74.5 \%$. On increasing the egg yolk concentration to $4 \%(\mathrm{v} / \mathrm{v})$ the emulsion stability showed a rise, $(0.83 \%$ breakage) revealed maximum phenol removal efficiency, as shown in Figure 4.
The results cited here reiterate that the extraction efficiency and emulsion stability depend particularly on the concentration of the surface-active agent. However, as evident from this Figure, when the egg yolk concentration increases to $5 \%(\mathrm{v} / \mathrm{v})$ the phenol extraction efficiency drops due to the resistance offered by the high mass transfer of the phenol transport at the internal oil interface. Several works in the literature mention this behavior (Kusumastuti et al. 2018, Mahakal 2018). Hence, the $4 \%(\mathrm{v} / \mathrm{v})$ concentration of the egg yolk was identified as the most suitable percentage for further experiments. Besides, when the egg yolk concentration increased from $3(\mathrm{v} / \mathrm{v})$ to $4 \%(\mathrm{v} / \mathrm{v})$, the stripping efficiency also escalated from 65.67 to $92.38 \%$ (as shown in Figure 4).

\section{Effect of homogenizer speed}

At high-speed, the rotation energy caused the dispersal of one liquid into another, creating the emulsion, as well as the break-down of the liquid into droplets. As the droplet size of the emulsion is clearly dependent upon the homogenizer speed, the droplet size reduces when the homogenizer speed is increased. This results in the expansion of the surface area of the droplet, which induces a higher rate of mass transfer during the course of the extraction.

This work investigated the effect of the homogenizer speed on emulsion stability. The stripping and extraction efficiency were checked at three rotation speeds $(3000,5800$, and 12700 rpm). The results shown in Figure 5 reveal the decrease in the breakage from 4.12 to $0.83 \%$ in response to the increase in the homogenizer speed from $3000 \mathrm{rpm}$ to $5800 \mathrm{rpm}$; the efficiency of the phenol extraction subsequently surged from 62.2 to $82.06 \%$. Another observation was an escalation

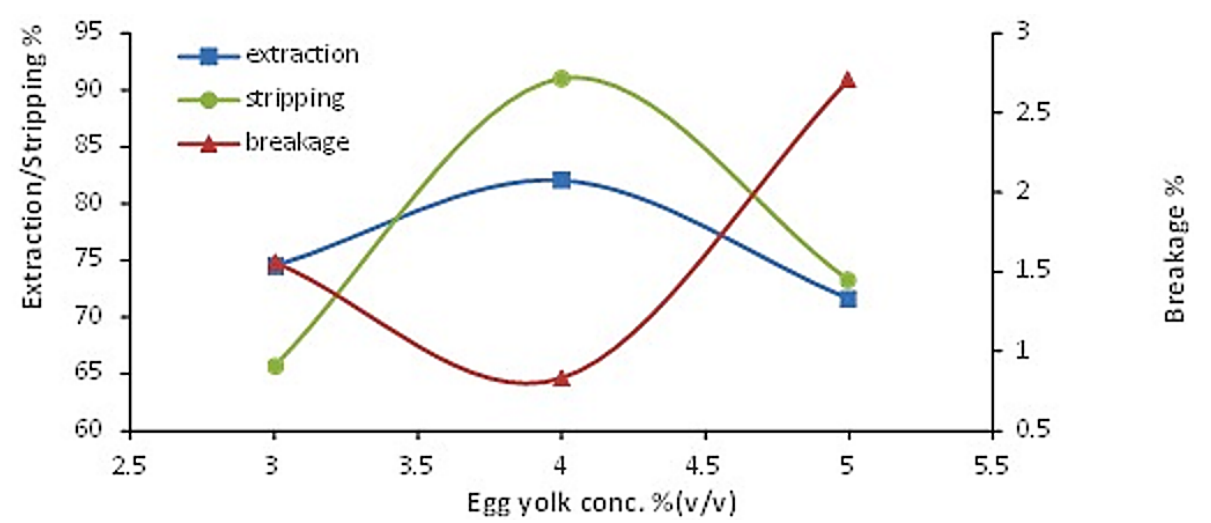

Figure 4. Effect of egg yolk concentration on extraction, stripping and breakage

$(\mathrm{O} / \mathrm{I}$ ratio $1: 1 ; 0.1 \mathrm{M} \mathrm{NaOH}$; homogenizer speed $5800 \mathrm{rpm}$; ET $7 \mathrm{~min}$; mixing speed $250 \mathrm{rpm}$ 


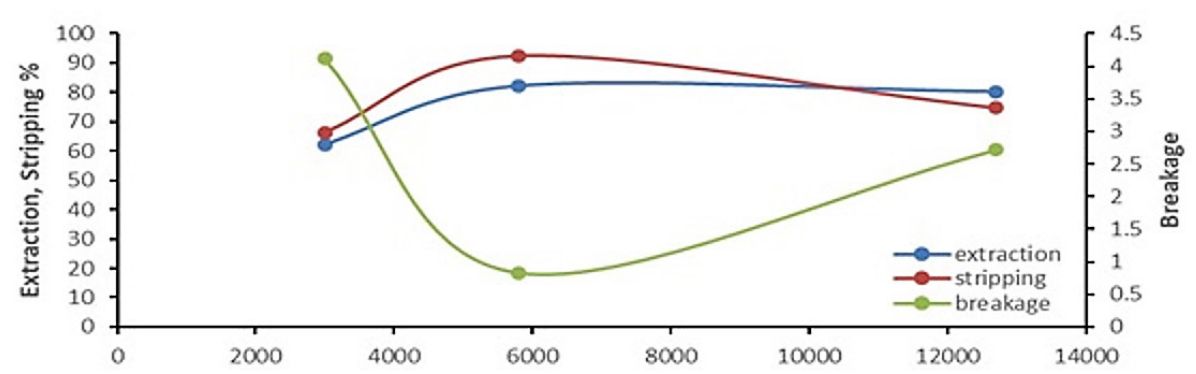

Figure 5. Homogenizer speed effect on the extraction, stripping and membrane breakage (4\% v/v EY; O/I ratio 1:1; 0.1M NaOH; ET 7 min; mixing speed 250 rpm)

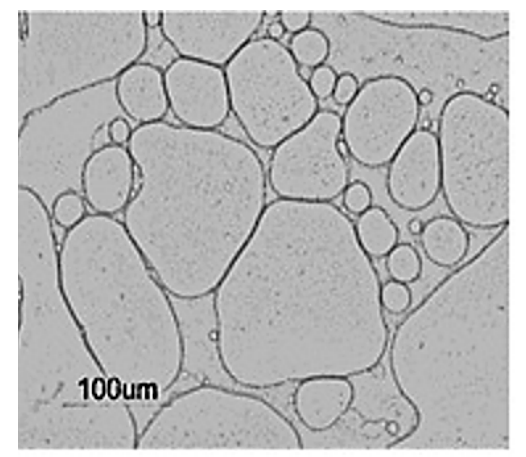

$3000 \mathrm{rpm}$

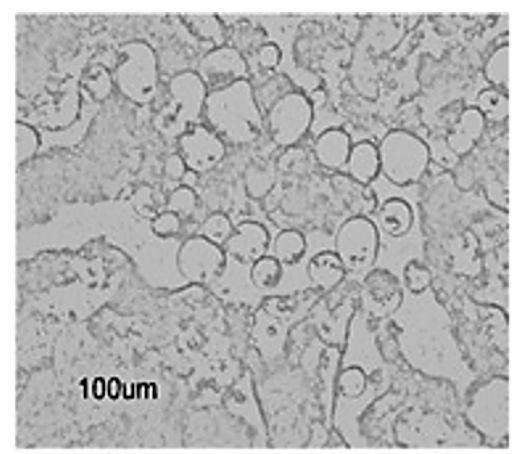

$5800 \mathrm{rpm}$

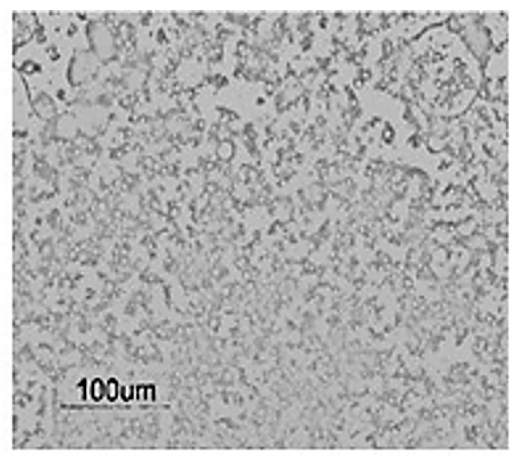

$12700 \mathrm{rpm}$

Figure 6. Optical microscopic image of the w/o emulsion droplets through different homogenizer speeds $(4 \%$ (v/v) EY; O/I ratio 1:1; $0.1 \mathrm{M} \mathrm{NaOH}$; ET 7 min; scale bar $=100 \mu \mathrm{m})$

in the breakage, in response to an increase in the homogenizer speed to $12,700 \mathrm{rpm}$, as well as a corresponding drop in both the extraction efficiency to $80.1 \%$ and the stripping efficiency to $74.6 \%$.

Figure 6 shows an optical microscopy image of w/o emulsion formed through different homogenizer speeds at 7 minutes of emulsification time. When the homogenizer speed was low $(3000 \mathrm{rpm})$ the droplet size grew larger (as shown in Figure 6) and the coalescence phenomenon happened in a brief time period. From a discussion of the results, the homogenizer speed of $5800 \mathrm{rpm}$ was chosen as the optimal speed for further experiments.

\section{Effect of emulsification time}

The emulsification time refers to the time taken for mixing during the preparation of the emulsion and is another factor which significantly influences the $\mathrm{W} / \mathrm{O}$ emulsion stability and thus the extraction efficiency. This study reveals the effect of the three different emulsification times $(4,7$, and $10 \mathrm{~min}$ ) on the emulsion stability and extraction efficiency of phenol. The results revealed that low emulsion stability and high breakage (2.81\%) occurred at a low emulsification time (4 min), lowering the extraction efficiency. Insufficient time for emulsification induced high emulsion breakage because the large droplet diameter caused the coalescence. However, an increase in the emulsification time to 7 minutes caused the breakage percent to drop to $0.83 \%$; interestingly, the longer emulsification time also induced breakage, due to the high internal shearing that caused a greater number of small droplets to get formed, by unit volume. In Figure 7, it is clear that by raising the emulsification time from 4 to 7 minutes, the extraction efficiency surged from 76.33 to $82.06 \%$; the stripping efficiency also soared from 86.5 to $91.3 \%$. After that, in response to the increase in the emulsification time to $10 \mathrm{~min}$, the stripping and the extraction efficiency dropped to $88.06 \%$ and $75.08 \%$, respectively. From these findings, an emulsification time of $7 \mathrm{~min}$. was selected for further experiments.

\section{Effect of $\mathrm{NaOH}$ concentration}

As the extraction step take place in the interface between the liquid membrane and the feed phase solution, the extraction of species 


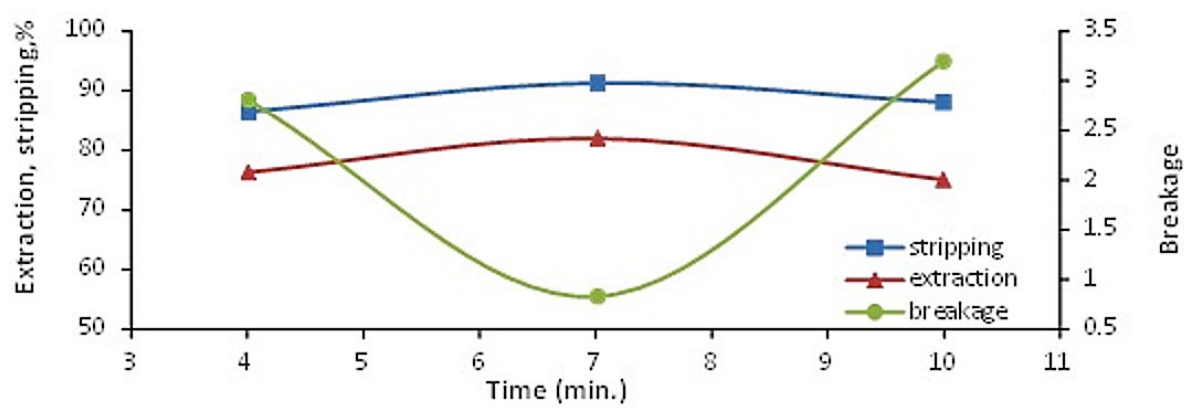

Figure 7. Emulsification time effect on the extraction, stripping and membrane breakage (4\% v/v EY; O/I ratio 1:1; 0.1M NaOH; homogenizer speed $5800 \mathrm{rpm}$; mixing speed $250 \mathrm{rpm}$ for $12 \mathrm{~min}$ )

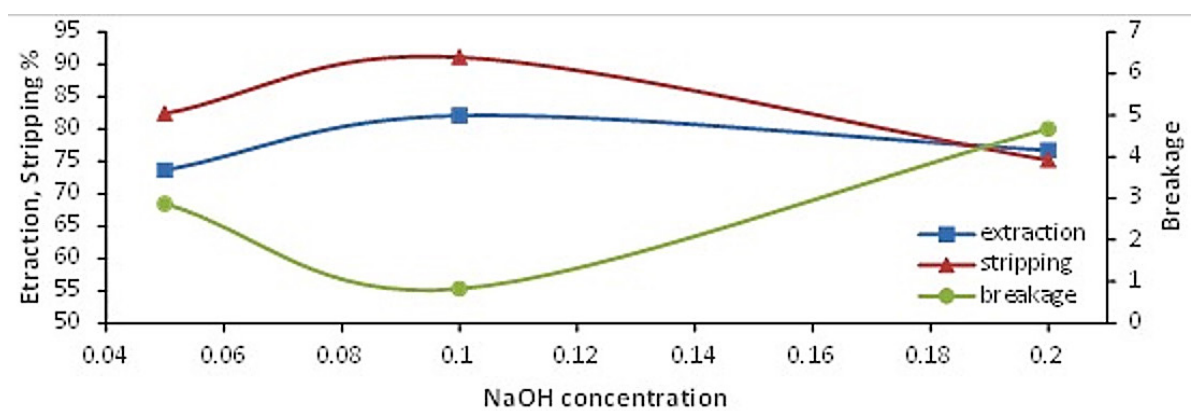

Figure 8. $\mathrm{NaOH}$ concentration effect on the extraction, stripping and membrane breakage (4\% v/v EY; O/I ratio 1:1; homogenizer speed $5800 \mathrm{rpm}$; mixing speed $250 \mathrm{rpm}$ )

necessarily requires a simultaneous stripping step at the opposite side of the membrane (Kumbasar 2008). In this study, investigation was also done on the influence exerted by the $\mathrm{NaOH}$ concentration on the degree of extraction so as to boost the regeneration of the membrane and increase the phenol concentration in the stripping phase. In Figure 8 it is evident that when the $\mathrm{NaOH}$ concentration was raised from 0.05 to $0.1 \mathrm{M}$, the percentage of breakage reduced from 2.87 to $0.83 \%$. On further increasing the $\mathrm{NaOH}$ concentration to $0.2 \mathrm{M}$ the breakage percent escalated. Besides, the phenol extraction and stripping efficiency intensified from 73.66 to $82.06 \%$ and from 82.4 to $91.1 \%$, respectively, when the $\mathrm{NaOH}$ concentration was boosted in the internal phase, from 0.05 to $0.1 \mathrm{M}$. Therefore, when the $\mathrm{NaOH}$ concentration was raised beyond $0.1 \mathrm{M}$, the phenol extraction and stripping efficiency were seen to decline. This was possibly because the increase in the $\mathrm{NaOH}$ concentration in the stripping phase reduced the difference in densities and built up the emulsion viscosity, which was reflected in the enhanced droplet sizes. Further, at the higher concentration of the sodium hydroxide, the emulsion stability declined, a reaction induced by the $\mathrm{NaOH}$-surfactant interaction. This also caused the partial loss of its surfactant properties resulting in the de-stabilization of the emulsion and lowered extraction efficiency (Dâas and Hamdaoui 2010). Therefore, in this study, the $0.1 \mathrm{M} \mathrm{NaOH}$ concentration was selected as it induced a higher extraction percentage and lower degree of breakage.

In Figure 9, the photograph images show the emulsion stability at different times. The photograph image of the fresh w/o emulsion reveals the complete stability of the emulsion, which after 24 hours shows the oil and the internal phase appearing to be separated from the emulsion.

\section{Effect of stirring speed}

The stirring speed plays a massive part in the rate of transport of the solution across the liquid membrane. Raising the agitation rates produces smaller sized globules, while an increase in the interfacial area between the membrane and feed phase enhances the mass transfer rate.

The influence exerted by the mixing speed on membrane stability, phenol extraction and stripping efficiency were investigated at speeds of 150, 250 and $350 \mathrm{rpm}$. As shown in Figure 10, it is clear that the increase in the stirring speed from 150 to $250 \mathrm{rpm}$ results in the extraction efficiency slowly rising from 78.2 to $82.06 \%$ with the stripping efficiency also up from 69.4 to $87.21 \%$. This 


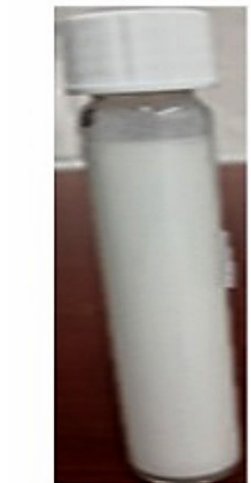

Fresh w/o Emulsion

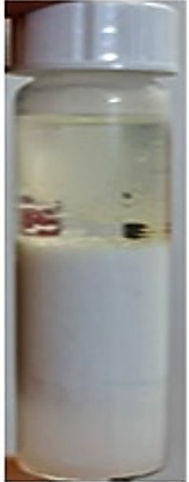

$24 \mathrm{~h}$

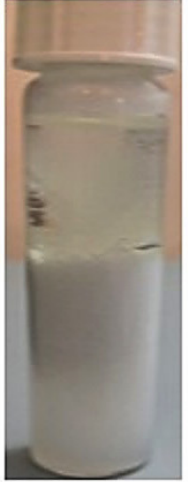

$10 d$

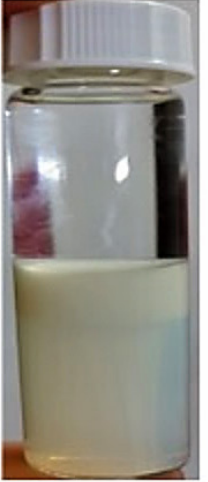

$30 d$

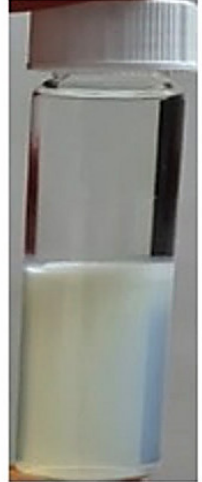

$60 d$

Figure 9. The emulsion at different time intervals: (4\%(v/v) egg yolk; $\mathrm{NaOH} 0.1 \mathrm{M}$; xylene as diluent; $5800 \mathrm{rpm}$ homogenizer speed, $7 \mathrm{~min}$ emulsification time and $\mathrm{O} / \mathrm{I}$ ratio 1:1

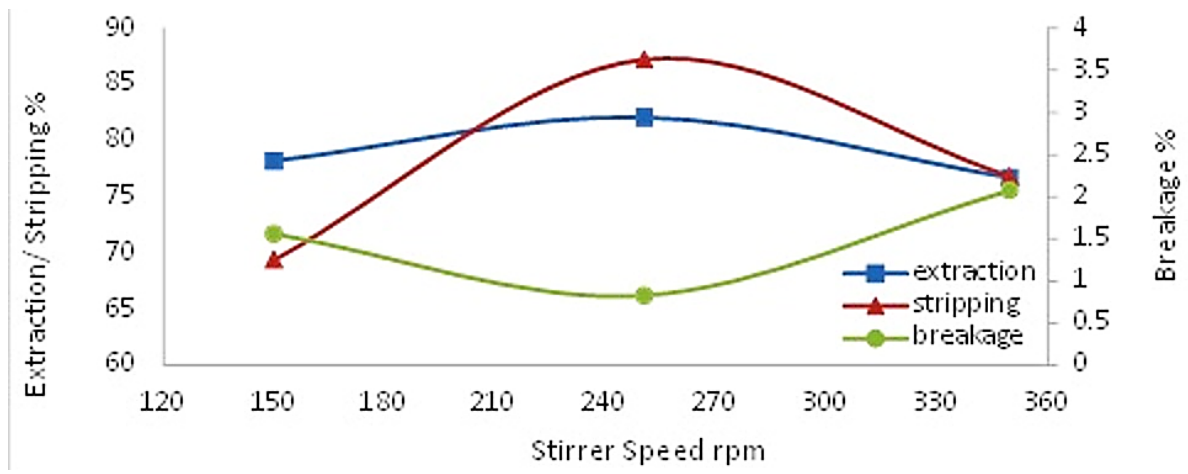

Figure 10. Stirrer speed effect on extraction, stripping and membrane breakage (4\% v/v EY; O/I ratio 1:1; speed of homogenizer $5800 \mathrm{rpm}$ )

occurs because of the reduction in the size of the emulsion globules and an augmentation of the interfacial area required for mass transfer when the mixing speed is increased. Any rise in the agitation speed beyond the critical value $(250 \mathrm{rpm})$ affects the membrane phase stability and boosts the osmotic swelling of the membrane. This leads to emulsion instability, which results in the decrease in the stripping and extraction efficiency to 80.2 and $76.7 \%$, respectively. Hence, $250 \mathrm{rpm}$ was found to give the highest extraction efficiency and was therefore selected in this study.

\section{EVALUATION OF MASS TRANSFER COEFFICIENT AND PHENOL EXTRACTION KINETIC}

The phenol extraction kinetic using the ELM method was estimated using the $1^{\text {st }}$ order rate, as evident in Eq. (4), following the similar technique performed by Raji et al. (2018) and Koli et al. (2019).

$$
\ln \left(\frac{C_{e}}{C_{e^{\circ}}}\right)=-k_{o b s} \cdot t
$$

where: $t$ represents the time in minutes and $k_{o b s}$ indicates the extraction rate constant $\left(\mathrm{min}^{-1}\right)$.

The slopes of the straight curves give the values of the constant extraction rate $\left(k_{o b s}\right)$ and because the slopes are negative, itis established that phenol extraction follows the $1^{\text {st }}$ order of kinetics. The constant of the extraction rate thus achieved was $0.1551 \cdot \mathrm{min}^{-1}$. Eq. (5) reveals the total mass transfer coefficient for the ELM system (Kasaini et al. 1998):

$$
\frac{1}{K_{T}}=\frac{1}{K_{M}}+\frac{1}{K_{F}}
$$

where: $K_{M}$ represents the mass transfer coefficient of the feed phase $(\mathrm{m} / \mathrm{s})$ determined by Skell and Lee correlation, see Eq. (6) (Raji et al. 2018):

$$
\begin{aligned}
& \frac{K_{m}}{\sqrt{\mathrm{ND}}=} 2.932 \times 10^{-7} \cdot \frac{\left(V_{i}+V_{m}\right)}{\left(V_{i}+V_{m}+V_{\mathrm{e}}\right)} . \\
& \cdot\left(\frac{d_{i}}{T}\right)^{0.548} \cdot \mathrm{Re}^{1.371}
\end{aligned}
$$


where: $N$ is the mixing speed of the agitated vessel; $T$ and $d_{i}$ refer to the diameters of the mixing tank and impeller, respectively. $V_{i}, V_{m}$, and $V_{e}$ are, respectively, the volumes of the internal, membrane and feed phases.

$R e$ represents the continuous phase Reynold number, which is calculated through Eq. (7):

$$
R_{e}=\frac{\left(\mathrm{Nd}_{\mathrm{I}}^{2} \cdot p_{c}\right)}{\mu_{\mathrm{C}}}
$$

The $R e$ value obtained was 15773.28 , where $D$ is the solute diffusivity in the membrane solvent, assessed using the Wilke and Chang correlation (Treybal 1981), see Eq. (8):

$$
\mathrm{D}=\frac{117.3 \times 10^{-18} \cdot(\varphi \mathrm{M})^{0.5} \mathrm{~T}}{\left(\mu_{\mathrm{m}} \varphi_{\mathrm{c}}^{0.6}\right)}
$$

The molecular weight of the solvent is given by $\mathrm{M}(106.16 \mathrm{~kg} / \mathrm{kmol}$ for xylene). The association factor of the solvent is indicated by $\varphi$ ( 1 for xylene). T signifies the Kelvin temperature and $\mu_{\mathrm{m}}$ is the viscosity of the organic phase $\left(0.731 \times 10^{-3}\right.$ $\mathrm{kg} / \mathrm{ms}$ ). The molar volume of the phenol is expressed as $\varphi_{\mathrm{c}}$, which is calculated using the Schroeder method (Poling et al. 2001). For phenol the value of $\varphi_{c}$ equals $0.089\left(\mathrm{~m}^{3} / \mathrm{kmol}\right)$.

$K_{F}$ represents the constant interfacial reaction rate $(\mathrm{m} / \mathrm{s})$, calculated through Eq. (9)

$$
\ln \left(\frac{C_{e}}{C_{e 0}}\right)=-A k_{F} \cdot t
$$

On comparing equations Eq. (9) and Eq. (4), $K_{F}$ can be identified through Eq. (10):

$$
K_{F}=\frac{K_{o b s}}{A}
$$

Where $A$ is the area of the emulsion specific interfacial, calculated by applying Eq. (11) (Karcher, Perrechil et al. 2015):

$$
A=\frac{A_{i}}{V}=\frac{6 \alpha}{d_{32}}
$$

In Table 3 the achieved mass transfer coefficients are listed.

Table 3. Phenol mass transfer coefficients in green surfactant emulsion liquid membrane

\begin{tabular}{|c|c|}
\hline Mass transfer coefficients $(\mathrm{m} / \mathrm{s})$ & Value \\
\hline $\mathrm{K}_{\mathrm{M}}$ & $1.3373 \times 10^{-5}$ \\
\hline $\mathrm{K}_{\mathrm{F}}$ & $1.302 \times 10^{-7}$ \\
\hline $\mathrm{K}_{\mathrm{T}}$ & $1.2894 \times 10^{-7}$ \\
\hline
\end{tabular}

\section{CONCLUSION}

The present study presents a novel and simple technique of preparing a stable ELM, using an environment-friendly green surfactant (egg yolk) in lieu of an artificial one. In this investigation three egg yolk concentrations were employed, utilizing the ability of the egg yolk to form an ELM that can extract and strip the phenol from the external phase. The green surfactant ELM was found to efficiently extract the phenol present in the aqueous solution. The emulsion included the following constituents: $4 \%(\mathrm{v} / \mathrm{v})$ egg yolk acting as the surfactant, xylene as the diluent, $0.1 \mathrm{M} \mathrm{NaOH}$ as the stripping phase, $5800 \mathrm{rpm}$ as the homogenizer speed, 7 minutes as the emulsification time and $250 \mathrm{rpm}$ as the stirrer speed. The results revealed the removal of $82.06 \%$ of phenol with $0.83 \%$ and $91.1 \%$ as the breakage and stripping efficiency respectively. The coefficient of the phenol mass transfer through ELM was also estimated. The final results of the mass transfer coefficient of the feed phase (KM), constant interfacial reaction rate (KF) and the total mass transfer coefficient (KT) achieved were respectively, $1.3373 \times 10^{-5}, 1.302 \times 10^{-7}$ and $1.2894 \times 10^{-7} \mathrm{~m} / \mathrm{s}$.

\section{REFERENCES}

1. Abdelwahab O., et al. 2009. Electrochemical removal of phenol from oil refinery wastewater. Journal of Hazardous Materials, 163(2-3), 711-716.

2. Ahmad, A., et al. 2012. Emulsion liquid membrane for cadmium removal: Studies on emulsion diameter and stability. Desalination, 287, 30-34.

3. Ahmed A. 2008. Electrocoagulation of phenol for wastewater treatment. Iraqi Journal of Chemical Petroleum Engineering, 9(3), 45-49.

4. Arutchelvan V., et al. 2006. Kinetics of high strength phenol degradation using Bacillus brevis. Journal of hazardous materials, 129(1-3), 216-222.

5. Bazrafshan E., et al. 2019. Photocatalytic degradation of catechol using $\mathrm{ZnO}$ nanoparticles as catalyst: Optimizing the experimental parameters using the Box-Behnken statistical methodology and kinetic studies. Microchemical Journal, 147, 643-653.

6. Chiha M., et al. 2010. Study on ultrasonically assisted emulsification and recovery of copper (II) from wastewater using an emulsion liquid membrane process. Ultrasonics sonochemistry, 17(2), 318-325.

7. Dâas A., Hamdaoui O.J.J.O.M.S. 2010. Extraction of bisphenol A from aqueous solutions by emulsion liquid membrane. Arabian Journal of Chemistry, 348(1-2), 360-368.

8. Dehmani Y., et al. 2020. Removal of phenol from aqueous solution by adsorption onto hematite 
$\left(\alpha-\mathrm{Fe}_{2} \mathrm{O}_{3}\right)$ : mechanism exploration from both experimental and theoretical studies. Arabian Journal of Chemistry, 13(5), 5474-5486.

9. Devulapalli R., Jones F. 1999. Separation of aniline from aqueous solutions using emulsion liquid membranes. Journal of Hazardous Materials, 70(3), 157-170.

10. Gürel L., et al. 2005. Removal of lead from wastewater using emulsion liquid membrane technique. Environmental Engineering Science, 22(4), 411-420.

11. Hernández-Francisco E., et al. 2017. Removal of phenolic compounds from oil refinery wastewater by electrocoagulation and Fenton/photo-Fenton processes. Journal of Water Process Engineering, 19, 96-100.

12. Hussein M.A., et al. 2019. Application of emulsion and Pickering emulsion liquid membrane technique for wastewater treatment: an overview. Environmental Science Pollution Research, 26(36), 36184-36204.

13. Jiang L., Mao X. 2012. Degradation of phenol-containing wastewater using an improved Electro-Fenton process. Int J Electrochem Sci, 7, 4078-4088.

14. Jiang Y., et al. 2010. Biodegradation of phenol and $\mathrm{m}$-cresol by mutated Candida tropicalis. Journal of Environmental Sciences, 22(4), 621-626.

15. Jiao H., et al. 2013. Extraction performance of bisphenol A from aqueous solutions by emulsion liquid membrane using response surface methodology. Desalination, 313, 36-43.

16. Karcher V., et al. 2015. Interfacial energy during the emulsification of water-in-heavy crude oil emulsions. Brazilian Journal of Chemical Engineering, 32(1), 127-137.

17. Kasaini H., et al. 1998. Application of emulsion liquid membranes to recover cobalt ions from a dualcomponent sulphate solution containing nickel ions. Journal of Membrane Science, 146(2), 159-168.

18. Kohli H.P., et al. 2019. Stability and performance study of emulsion nanofluid membrane: A combined approach of adsorption and extraction of Ethylparaben. Colloids Surfaces A: Physicochemical Engineering Aspects, 579, 123675.

19. Kumbasar R.A. 2008. Selective separation of chromium (VI) from acidic solutions containing various metal ions through emulsion liquid membrane using trioctylamine as extractant. Separation purification technology, 64(1), 56-62.

20. Kusumastuti, A., et al. 2018. Emulsion liquid membrane for textile dyes removal: Extraction process. Journal of Physical Science, 29, 175-184.

21. Mahakal P.A., Deshpande R.S. 2018. Removal of heavy metal from aqueous wastewater by emulsion liquid membrane. International Journal of Advanced Research, 6(1), 455-463.

22. Mahvi A.H., et al. 2007. Photo-oxidation of phenol in aqueous solution: toxicity of intermediates. Korean Journal of Chemical Engineering, 24(1), 79-82.

23. Mohammed A.A., et al. 2020. Studies on membrane stability and extraction of ciprofloxacin from aqueous solution using pickering emulsion liquid membrane stabilized by magnetic nano- $\mathrm{Fe}_{2} \mathrm{O}_{3}$. Colloids Surfaces A: Physicochemical Engineering Aspects, 585, 124044.

24. Mohammed A.A., et al. 2020. Simultaneous studies of emulsion stability and extraction capacity for the removal of tetracycline from aqueous solution by liquid surfactant membrane. Chemical Engineering Research Design, 159, 225-235.

25. Mohammed A.A., Selman H.M. 2018. Liquid surfactant membrane for lead separation from aqueous solution: Studies on emulsion stability and extraction efficiency. Journal of environmental chemical engineering, 6(6), 6923-6930.

26. Moussavi G., et al. 2009. The investigation of catalytic ozonation and integrated catalytic ozonation/ biological processes for the removal of phenol from saline wastewaters. Journal of Hazardous Materials, 171(1-3), 175-181.

27. Park Y. 2006. Development and optimization of novel emulsion liquid membranes stabilized by non-newtonian conversion in taylor-couette flow for extraction of selected organic and metallic contaminants, Georgia Institute of Technology.

28. Poling B.E., et al. 2001. The properties of gases and liquids, Mcgraw-hill New York.

29. Raji M., et al. 2018. Response Surface Optimization of Dysprosium Extraction Using an Emulsion Liquid Membrane Integrated with Multi-Walled Carbon Nanotubes. Chemical Engineering Technology, 41(9), 1857-1870.

30. Raji M., et al. 2017. Nanofluid-based emulsion liquid membrane for selective extraction and separation of dysprosium. International Journal of Chemical Molecular Engineering, 11(12), 787-792.

31. Roostaei N., Tezel F.H.J.J.O.E.M. 2004. Removal of phenol from aqueous solutions by adsorption. Journal of Environmental Management, 70(2), 157-164.

32. Sabry R., et al. 2007. Removal of lead by an emulsion liquid membrane: Part I. Desalination, 212(13), 165-175.

33. Seifollahi Z., et al. 2019. Amoxicillin extraction from aqueous solution by emulsion liquid membranes using response surface methodology. Chemical Engineering Technology, 42(1), 156-166.

34. Shibata A., et al. 2006. Aerobic and anaerobic biodegradation of phenol derivatives in various paddy soils. Science of the Total Environment, 367(2-3), 979-987.

35. Treybal R.E. 1981. Mass - Transfer Operations, third ed., McGraw-Hill Book Co, Singapore.

36. Verschueren K. 1977. Handbook of environmental data of organic compounds. Van Nostrand Reinhold Co., 525.

37. Wilberg K.D.Q., et al. 2000. Removal of phenol by enzymatic oxidation and flotation. Brazilian Journal of Chemical Engineering, 17, 907-914.

38. Zhao X., Wang Y., Ye Z., Borthwick A.G.L., Ni J. 2006. Oil field wastewater treatment in Biological Aerated Filter by immobilized microorganisms. Process Biochemistry, 41(7), 1475-1483. 